of California San Francisco, World Health Organisation, City and County of San Francisco, American Foundation for AIDS Research, International AIDS Society, 1990:295.

44 Steel CM, Ludlam CA, Beatson D, et al. HLA haplotype Al B8 DR3 as a risk factor for HIV-related disease. Lancet 1988;i:1185-8.

45 Mann DL, Murray C, Yarchoan R, Blattner WA, Goeddert JJ. HLA antigen frequencies in HIV-I seropositive disease-free individuals and patients with AIDS fournal of AIDS 1988:1:13-7.

46 Ranki A, Valle SL, Krohn M, et al. Long latency precedes overt seroconversion in sexually transmitted human immunodeficiency virus infection. Lancet 1987; ii: 589-93.

47 Wolinsky SM, Rinaldo CR, Kwok S, et al. Human immunodeficiency virus type 1 (HIV-1) infection a median of 18 months before a diagnostic western blot: evidence from a cohort of homosexual men. Ann Intern Med 1989;111 $961-72$
48 Imagawa DT, Lee MH, Wolinsky SM, et al. Human immunodeficiency virus type 1 infection in homosexual men who remain seronegative for prolonged periods. N Engl f Med 1989;321:1458-62.

49 Horsburgh CR, Ou CY, Holmberg SD, et al. Human immunodeficiency virus type 1 infection in homosexual men who remain seronegative for prolonged

50 Lifson AR, Stanley M, Pane J, et al. Detection of human imunodeficiency virus DNA using the polymerase chain reaction in a well characterized group of homosexual and bisexual men. F Infect Dis 1990;161:436-9.

51 Horsburgh CR, Ou Cy, Jason J, et al. Duration of human immunodeficiency virus infection before detection of antibody. Lancet 1989;ii:637-40.

52 Volberding PA, Lagakos SW, Koch MA, et al. Zidovudine in asymptomatic human immunodeficiency virus infection. $N$ Engl f Med 1990;322:941-9.

(Accepted 22 October 1990)

\title{
Diagnosis of abdominal masses with percutaneous biopsy guided by ultrasound
}

\author{
H J Jaeger, J MacFie, C J Mitchell, N Couse, D Wai
}

\section{Abstract}

Objective-To assess the accuracy and safety of percutaneous biopsy of abdominal masses guided by ultrasound.

Design-Prospective study.

Setting-Combined gastroenterology service, Scarborough Hospital.

Patients - 108 Consecutive patients identified as having a discrete mass on diagnostic ultrasound examination of the abdomen.

Intervention-A sample of tissue was obtained with an aseptic technique under local anaesthesia: an 18 steel wire gauge needle (Tru-Cut) was mounted in a spring loaded firing device (Biopty gun) that was advanced under simultaneous ultrasound scanning, permitting precise localisation of the target organ.

Main outcome measure-Results of histological examination of tissue specimens.

Results-Biopsy failed in four patients. Adequate histological specimens were obtained in 104 patients with masses in the liver (31), pancreas (37), kidney (10), and adrenal glands (six) and in 20 undiagnosed abdominal and retroperitoneal masses. Follow up was until death or confirmation of the diagnosis. Three complications but no deaths occurred. Malignancy was suspected in 84 patients before biopsy. This was confirmed in 70 patients, in 26 of whom confirmation of dissemination obviated the need for further investigation. In 10 patients biopsy indicated a previously unsuspected primary tumour, and in $\mathbf{1 2}$ it showed only a benign lesion. Among 24 patients considered to have benign disease biopsy showed an unsuspected neoplasm in seven. Use of biopsy thus had a major effect on clinical management in 55 patients. Four false negative but no false positive diagnoses resulted from the procedure.

Conclusion-Percutaneous biopsy of abdominal and retroperitoneal masses under ultrasound guidance is a safe and accurate method of obtaining a histological diagnosis. The results obtained have a considerable effect on clinical management.

H J Jaeger, $\mathrm{MB}$, senior house officer in general surgery

$\mathrm{J}$ MacFie, FRCs, consultant surgeon

C J Mitchell, FRCP, consultant physician

N Couse, FRCSI, surgical registrar

D Wai, FRCR, consultant radiologist

Correspondence to:

Dr Mitchell. nancy, in whom surgery is often hazardous. Attempts to overcome this problem with percutaneous biopsies with large gauge needles have had only limited success

An important obstacle in managing patients with difficulty in safely obtaining an accurate diagnosis on the results of histological examin without doing a laparotomy. This is particularly important in elderly patients with suspected malig- because of considerable associated morbidity. ${ }^{12}$ Many authors recommend using fine needle aspiration cytology, but this requires specialist skills, which are not always available. ${ }^{3-7}$

More recently a system has been developed that enables biopsy of the targeted organ to be performed percutaneously with ultrasound guidance. ${ }^{8}$ The tissue specimens obtained are suitable for routine histological examination. After successfully applying this technique to biopsy of the pancreas ${ }^{9}$ we applied it more generally in investigating patients with abdominal masses. We report our initial experience with particular reference to the accuracy and safety of the technique.

\section{Patients and methods}

We analysed prospectively 108 consecutive patients who presented to our combined gastroenterology service over three years in whom abdominal ultrasound scanning confirmed the presence of a clinically or radiologically suspected mass or identified a previously undetected discrete mass. In many cases malignancy was suspected and it was important to confirm or exclude the presence of disseminated disease. Thirty two patients underwent percutaneous biopsy, guided by ultrasound, of lesions of the liver. In 13 patients with hepatomegaly ultrasound scanning showed single (seven) or multiple (six) lesions. Eleven patients with proved malignant disease were scanned to exclude liver metastases. In eight patients ultrasound scanning was performed to investigate non-specific abdominal symptoms.

Twenty patients underwent biopsy of abdominal or retroperitoneal lesions. Six had a palpable abdominal mass, and two presented with abdominal pain but had no abnormalities on examination or on contrast radiological examination. Six patients underwent biopsy of para-aortic or retroperitoneal lymph nodes, of whom two had received treatment for lymphoma. Three patients with abnormal results of liver function tests had portal lymphadenopathy on ultrasound examination. Two patients underwent biopsy of the pylorus after equivocal findings on endoscopy and radiological examination. One patient in whom the result of endoscopic retrograde cholangiopancreatography was equivocal had a lesion identified in the choledochojejunal anastomosis from a previous Whipple's operation. All but six of this group had other extensive investigations before ultrasound scanning identified a mass.

Ten patients underwent biopsy of renal masses; in six these were an incidental finding at intravenous urography. Two patients had had a nephrectomy for 
carcinoma, and recurrence was suspected. A renal mass was found on computed tomography in one patient with acute pancreatitis. The remaining patient had myelomatosis. Six patients underwent biopsy of adrenal masses; in four of these metastatic deposits were suspected, and two were being investigated for general malaise.

Biopsy of the pancreas was performed in 40 patients with a mass detected by ultrasound scanning. Most of these patients (28) were considered to have pancreatic carcinoma and 16 were jaundiced. Chronic pancreatitis had been diagnosed clinically in six patients. Six patients had pancreatic cysts, of whom two had chronic pancreatitis and four acute pancreatitis. Thirty of these patients were included in a previous report ${ }^{9}$ but are included in this series for completeness.

All patients fasted for six hours before biopsy. A coagulation screen was performed and serum grouped and saved. No antibiotic prophylaxis was given. All patients were observed for a minimum of 24 hours after the procedure, but no restrictions on eating or drinking were imposed unless clinically indicated. Patients were followed up until death or confirmation of the diagnosis.

The biopsy technique was originally described by Lindgren for hepatic and renal biopsy. ${ }^{8}$ All biopsies were performed with a real time ultrasound machine. Initially, detailed scanning was performed to plan the route of the biopsy. The entry point was marked on the skin and, using an aseptic technique, the biopsy track was infiltrated with $2 \%$ lignocaine to the peritoneum. An 18 steel wire gauge biopsy needle (Tru-Cut) was mounted in an automatic firing device with a spring loaded mechanism (Biopty, Radiplast $A B$, Uppsala) that was operated with one hand, permitting simultaneous scanning. The needle tip and its track during biopsy were shown ultrasonically, ensuring precise sampling of the target lesion. The biopsy needle was advanced under continuous ultrasound guidance to the edge of the mass. The trigger mechanism was then activated and the needle with drawn.

Biopsy specimens were fixed in $10 \%$ formalin and embedded in paraffin wax. In most patients a firm diagnosis was made with standard stains. Additional microbiological and immunological stains were used when necessary.

\section{Results}

Complications occurred in three patients. These were minor in two, one of whom developed transient abdominal pain and the other a haematoma that resolved without treatment. The only severe complication was septicaemia in a jaundiced patient in whom biopsy confirmed carcinoma of the head of the pancreas; this resolved after treatment with antibiotics, and she subsequently had a successful Whipple's operation. No deaths related to the biopsy occurred. In four patients biopsy yielded insufficient tissue for histological examination, but adequate specimens were obtained in the remaining 104 patients.

\section{SUSPECTED MALIGNANT LESIONS}

Malignancy was suspected in 84 patients after clinical assessment and investigation (table I). Biopsy failed in two patients. Twelve of these patients proved to have benign disease, and follow up did not result in a change in the diagnosis ("unsuspected benign disease," table I). In 10 patients the clinical diagnosis of malignancy was confirmed but histological examination showed that the primary tissue of origin was different from that suspected ("altered primary"). This group included four patients considered to have primary or metastatic liver cancer who proved to have carcinoid; four patients considered to have pancreatic carcinoma in whom histological examination showed ampullary, gastric, and metastatic carcinoma and lymphoma; and two patients in whom suspected primary liver cell cancer or hypernephroma proved to be metastatic adenocarcinoma.

Metastatic disease was diagnosed in 26 patients with suspected malignancy ( 13 with liver, five with adrenal, and eight with abdominal masses), which obviated the need for further investigation. In 31 patients, including 20 with pancreatic carcinoma, the biopsy confirmed the clinical and ultrasound diagnosis of a primary carcinoma.

Follow up showed that biopsy yielded false negative diagnoses in three patients suspected of having malignant lesions. Biopsy in one patient showed cirrhosis, although she was suspected to have a hepatoma and this proved to be the case at later necropsy; in two other patients considered to have metastatic liver disease the results of biopsy were normal or showed necrotic tissue, but both patients died within three months and were proved to have carcinomatosis.

TABLE I-Clinical diagnosis and histological diagnosis after biopsy in 84 patients with suspected malignancy

\begin{tabular}{|c|c|c|c|}
\hline Clinical diagnosis & Histological diagnosis & No & Comments \\
\hline Adrenal tumour $(n=6)$ & $\begin{array}{l}\text { Metastatic adenocarcinoma } \\
\text { Hyperplasia }\end{array}$ & $\begin{array}{l}5 \\
1\end{array}$ & Unsuspected benign disease \\
\hline Pancreatic carcinoma $(n=28)$ & $\begin{array}{l}\text { Diagnosis confirmed } \\
\text { Chronic pancreatitis } \\
\text { Extrapancreatic neoplasm } \\
\text { Failed biopsy }\end{array}$ & $\begin{array}{r}20 \\
2 \\
4 \\
2\end{array}$ & $\begin{array}{l}\text { Unsuspected benign disease } \\
\text { Altered primary }\end{array}$ \\
\hline Clear cell carcinoma $(n=6)$ & $\begin{array}{l}\text { Diagnosis confirmed } \\
\text { Norrnal } \\
\text { Metastatic adenocarcinoma }\end{array}$ & $\begin{array}{l}3 \\
2 \\
1\end{array}$ & $\begin{array}{l}\text { Unsuspected benign disease } \\
\text { Altered primary }\end{array}$ \\
\hline Primary liver cell carcinoma $(n=9)$ & $\begin{array}{l}\text { Diagnosis confirmed } \\
\text { Carcinoid } \\
\text { Metastatic adenocarcinoma } \\
\text { Cirrhosis }\end{array}$ & $\begin{array}{l}2 \\
1 \\
1 \\
3\end{array}$ & $\begin{array}{l}\text { Altered primary } \\
\text { Altered primary } \\
\text { Unsuspected benign disease (2), } \\
\text { false negative finding (1) }\end{array}$ \\
\hline Adenocarcinoma liver metastatic $(n=15)$ & $\begin{array}{l}\text { Diagnosis confirmed } \\
\text { Carcinoid } \\
\text { No malignancy } \\
\text { Subacute necrosis }\end{array}$ & $\begin{array}{r}13 \\
3 \\
2 \\
1\end{array}$ & $\begin{array}{l}\text { Altered primary } \\
\text { False negative findings } \\
\text { Unsuspected benign disease }\end{array}$ \\
\hline Lymphoma $(n=4)$ & $\begin{array}{l}\text { Diagnosis confirmed } \\
\text { Mycobacterium avium infection }\end{array}$ & $\begin{array}{l}3 \\
1\end{array}$ & $\begin{array}{l}\text { Unsuspected benign disease } \\
\text { (HIV positive) }\end{array}$ \\
\hline Lymphatic metastasis (porta hepatis) $(\mathrm{n}=3$ ) & $\begin{array}{l}\text { Diagnosis confirmed (cholangiocarcinoma) } \\
\text { Reactive change }\end{array}$ & $\begin{array}{l}1 \\
2\end{array}$ & Unsuspected benign disease \\
\hline $\begin{array}{l}\text { Myeloma }(n=1) \\
\text { Retroperitoneal sarcoma }(n=1) \\
\text { Pyloric carcinoma }(n=1) \\
\text { Anastomotic recurrence }(\text { after Whipple's operation })(n=1) \\
\text { Intra-abdominal metastasis }(n=7)\end{array}$ & $\begin{array}{l}\text { Pyelonephritis } \\
\text { Liposarcoma } \\
\text { Diagnosis confirmed } \\
\text { Diagnosis confirmed } \\
\text { Diagnosis confirmed }\end{array}$ & $\begin{array}{l}1 \\
1 \\
1 \\
1 \\
7\end{array}$ & Unsuspected benign disease \\
\hline
\end{tabular}

^Ampullary (1), gastric (1), metastatic (1), lymphoma (1). 
TABLE II-Clinical diagnosis and histological diagnosis after biopsy in 24 patients with suspected benign diseas

\begin{tabular}{|c|c|c|c|}
\hline Clinical diagnosis & Histological diagnosis & No & Comments \\
\hline Chronic pancreatitis $(n=6)$ & $\begin{array}{l}\text { Diagnosis confirmed } \\
\text { Insulinoma } \\
\text { Failed biopsy }\end{array}$ & $\begin{array}{l}4 \\
1 \\
1\end{array}$ & $\begin{array}{l}\text { False negative result ( } 1) \\
\text { Unsuspected malignancy }\end{array}$ \\
\hline Pancreatic pseudocyst $(n=6)$ & $\begin{array}{l}\text { Pancreatitis } \\
\text { Cystadenocarcinoma }\end{array}$ & $\begin{array}{l}5 \\
1\end{array}$ & Unsuspected malignancy \\
\hline Mesenteric cyst $(n=2)$ & $\begin{array}{l}\text { Dermoid cyst } \\
\text { Lymphoma }\end{array}$ & $\begin{array}{l}1 \\
1\end{array}$ & Unsuspected malignancy \\
\hline Renal cyst $(n=2)$ & $\begin{array}{l}\text { Clear cell carcinoma } \\
\text { Diagnosis confirmed }\end{array}$ & $\begin{array}{l}1 \\
1\end{array}$ & Unsuspected malignancy \\
\hline $\begin{array}{l}\text { Haemangioma }(\text { kidney })(n=1) \\
\text { Psoas haematoma }(n=1)\end{array}$ & $\begin{array}{l}\text { Clear cell carcinoma } \\
\text { Plasmacytoma }\end{array}$ & $\begin{array}{l}1 \\
1\end{array}$ & $\begin{array}{l}\text { Unsuspected malignancy } \\
\text { Unsuspected malignancy }\end{array}$ \\
\hline Liver cyst $(\mathrm{n}=3)$ & $\begin{array}{l}\text { Diagnosis confirmed } \\
\text { Equivocal }\end{array}$ & $\begin{array}{l}2 \\
1\end{array}$ & Carcinoma excluded at laparotomy \\
\hline Hepatic steatosis $(\mathbf{n}=2)$ & $\begin{array}{l}\text { Metastatic adenocarcinoma } \\
\text { Failed biopsy }\end{array}$ & $\begin{array}{l}1 \\
1\end{array}$ & Unsuspected malignancy \\
\hline Hepatic abscess $(n=1)$ & Hepatitis & 1 & \\
\hline
\end{tabular}

TABLE III-Details of follow up until death or confirmation of diagnosis at laparotomy of patients with malignancy or benign disease, excluding those in whom biopsy failed or yielded false negative results

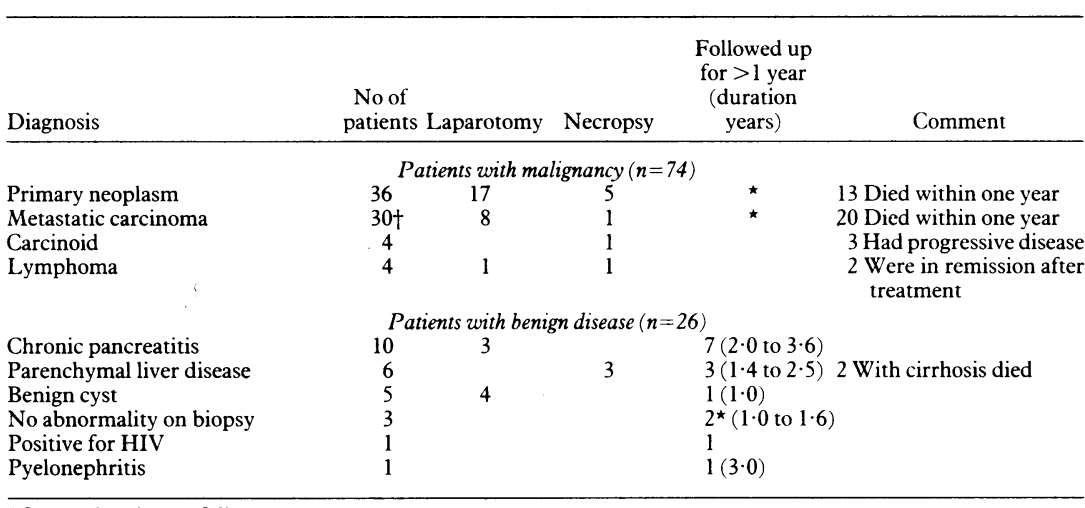

*One patient lost to follow up.

fIn seven patients a primary tumour was subsequently found.

Thus in 22 patients with suspected malignant lesions (12 with unsuspected benign masses and 10 with altered primary tissue) a different diagnosis was established, and in 26 disseminated malignancy was confirmed.

\section{SUSPECTED BENIGN LESIONS}

Among the 24 patients with a clinical diagnosis of benign disease biopsy was unsuccessful in two (table II). Biopsy in seven cases showed malignancy. One false negative result occurred: biopsy confirmed the clinical diagnosis of chronic pancreatitis, but on histological examination after excisional surgery adenocarcinoma in association with chronic pancreatitis was identified.

\section{FOLLOW UP}

Follow up of patients was by review in the outpatient department or until death or confirmation of the diagnosis after laparotomy (table III). At the time of writing the diagnosis reached by means of biopsy, in particular the presence or absence of malignancy, was incorrect in four patients as described above. Biopsy did not yield any false positive results.

Among the 74 patients in whom malignant disease was diagnosed by biopsy this was confirmed at laparotomy or necropsy in 34. A further 33 patients died within one year, and five were still alive (three with metastatic carcinoid and two with lymphoma in remission after treatment). Two patients were lost to follow up. Among the 26 patients in whom benign disease was diagnosed by biopsy this was confirmed in 11 at laparotomy or necropsy. Apart from one patient lost to follow up, the remainder were alive after at least one year and their disease was pursuing its expected clinical course; the patients with chronic pancreatitis were all followed up for at least two years so that a missed carcinoma was improbable.

\section{Discussion}

Use of abdominal ultrasound scanning to investigate patients with gastroenterological disorders is common. In patients with a palpable mass it may identify the tissue of origin but further investigations are often required to establish a firm diagnosis without laparotomy. In many other patients, as shown in this series, ultrasound scanning detects a previously unsuspected abdominal mass, the clinical importance of which may be unclear. Clearly, managing any patient with an abdominal mass is greatly helped by a knowledge of its histology.

In 1982 Lindgren described a percutaneous needle biopsy technique for the kidney and liver with several practical advantages. ${ }^{8}$ Ultrasound scanning can continue during biopsy to confirm that the correct target has been sampled. The biopsy specimen is large enough for histological assessment. Reported experience, however, is limited. In an initial series of 45 hepatic and renal biopsies the technique proved to be safe and accurate. ${ }^{8}$ Donald et al used the method successfully to obtain biopsy specimens of lymph nodes in six patients positive for HIV and referred to its safety in an unpublished study of 200 intra-abdominal biopsies. ${ }^{10} \mathrm{We}$ have reported successfully applying the technique to pancreatic biopsy, and Parker et al have described their experience in a heterogenous group of patients in whom computed tomography and fluoroscopic guidance were used in addition to ultrasound guidance. ${ }^{911}$

Our results suggest that there are few disadvantages associated with the technique. Biopsy was impracticable or failed to provide an adequate specimen in only $4 \%$ of the series. Three complications (one of which was serious) but no deaths occurred. Tumour seeding is a theoretical problem but did not occur in this series. These results compare favourably with those reported for fine needle aspiration biopsy. Mortality associated with fine needle aspiration biopsy is negligible, and serious complications are rare; the technique's safety is a consequence not only of the fine needle used but also of the accurate localisation of the target organ with ultrasound scanning or computed tomography before biopsy. The low incidence of complications of percutaneous biopsy guided by ultrasound in this series must also reflect the accuracy of localisation before biopsy.

No false positive diagnoses and only four false negative diagnoses occurred in this series. The absence of false positive diagnoses means that the positive predictive value approaches $100 \%$, which has enormous implications for managing patients.

The sensitivity of fine needle aspiration biopsy for abdominal malignancies is $65-95 \%,{ }^{3-6}$ depending on selection criteria as well as the skill of the operators. ${ }^{12}$ An experienced cytologist and good technique are necessary for success, but these constraints do not apply to percutaneous biopsy guided by ultrasound. Good ultrasound scanning is now widely available, as is the skill to interpret histological specimens. The results of this series suggest that the sensitivity of percutaneous biopsy guided by ultrasound will be comparable with or better than that of fine needle aspiration biopsy and the method will not be limited to specialist centres.

We accept that the diagnosis obtained from percutaneous biopsy guided by ultrasound was not confirmed independently by necropsy or surgical histological examination for all patients. All except five patients with malignant disease, however, did have confirmation by surgery or biopsy or died within one year. Of these five patients, two had lymphoma, which went into remission, and three had metastatic carcinoid, which progressed clinically and radiologically as expected. Follow up in the patients with benign 
disease unconfirmed by laparotomy or necropsy was sufficiently long to make an erroneous diagnosis extremely unlikely. We conclude that our incidence of false negative and false positive diagnosis is unlikely to change, particularly as the four false negative diagnoses were all identified within six months of biopsy.

The potential clinical benefits of biopsy guided by ultrasound are well illustrated in this series. The addition of histological sampling to the ultrasound evaluation corrected the erroneous clinical diagnosis of malignancy in a tenth of patients as well as identifying the correct primary tissue in a further tenth. We thus considerably increased our diagnostic accuracy with major implications for treatment. In a further 26 patients, a quarter of this series, confirming metastatic malignancy removed the need for laparotomy. As the main objective in such patients is effective palliation, avoiding surgery with its morbidity and mortality is beneficial. The need or otherwise for surgery and other invasive investigations also has important implications for costs. Our study suggests that this technique will effect considerable savings because a firm diagnosis is obtained quickly. These financial benefits are enhanced because the technique does not require expensive equipment or additional staff.

The biopsy also allows pathologists to use additional microbiological or immunological stains. In one patient positive for HIV Mycobacterium avium-intracellulare was shown and the clinical diagnosis of lymphoma refuted. Few cytologists are confident in diagnosing lymphoma, and the sensitivity of fine needle aspiration biopsy in this condition has been reported to be as low as $40 \% .^{13}$ The availability of a tissue specimen from biopsy guided by ultrasound should facilitate an accurate pathological diagnosis in this difficult group of patients.

We conclude that biopsy guided by ultrasound as described here is a safe and reliable method of establishing the histological diagnosis of abdominal and retroperitoneal masses and influences clinical management considerably.

We thank consultant colleagues at this hospital who allowed us to study their patients. In particular, we thank Dr A M Jackson, consultant pathologist.

1 Fisher CJ, Falloon WW. Needle biopsy of the liver. Comparison of initial clinical and histological diagnosis, with a note on post biopsy mortality in patients with metastatic neoplasm. Am F Med 1958;253:368-73.

2 Isaacson R, Weiland LH, McIlrath DC. Biopsy of the pancreas. Arch Surg 1975;19:227-30.

3 Ferrucci JT, Wittenberg J, Mueller PR, et al. Diagnosis of abdominal malignancy by radiologic fine needle aspiration biopsy. AfR 1980;134 323-30

4 Frable WJ. Fine-needle aspiration biopsy. Hum Pathol 1983;14:9-18.

5 Hall-Craggs MA, Lees WR. Fine needle biopsy: cytology, histology or both? Gut 1987;28:233-6.

6 Hall-Craggs MA, Lees WR. Fine-needle aspiration biopsy: pancreatic and biliary tumors. AfR 1986;147:399-403.

7 Lees WR, Hall-Craggs MA, Manhire AR. Five years' experience of fine needle aspiration biopsy: 454 consecutive cases. Clin Radiol 1985;36:517-20.

8 Lindgren PG. Percutaneous needle biopsy: a new technique. Acta Radiol 1982:2:653-6.

9 Mitchell CJ, Wai D, Jackson AM, MacFie J. Ultrasound guided percutaneous pancreatic biopsy. Br f Surg 1989;76:706-7.

10 Donald JJ, Coral A, Shorvon PJ, Lees WR. Ultrasound guided core biopsy in AIDS; experience in six patients. BMf 1988;296:606-7.

11 Parker SH, Hopper KD, Yakes WF, et al. Image directed percutaneous biopsies with a biopsy gun. Radiology 1989;171:663-9.

12 Yeh HC. Percutaneous fine needle aspiration biopsy of intra-abdominal lesion with ultrasound guidance. Am $\mathcal{F}$ Gastroenterol 1981;75:148-52.

13 Zornoza J, Wallace S, Goldstein HM, et al. Transperitoneal percutaneous retroperitoneal lymph node aspiration biopsy. Radiology 1977;122:111-5.

(Accepted 31 August 1990)

\title{
Junior doctors' on call activities: differences in workload and work patterns among grades
}

\author{
Nancy B Turnbull, Norman A Miles, Ian W Gallen
}

Medical School,

University of Nottingham

Nancy B Turnbull, BA,

research assistant

\section{Nottingham Health}

Authority, Nottingham

NG3 5AF

Norman A Miles, FFPHM, consultant in public health medicine

University Hospital, Nottingham

Ian W Gallen, MRCP, registrar

Correspondence to:

Dr Miles.

Br.Med f 1990;301:1191-2

\section{Abstract}

Objective-To examine the workload and work patterns of junior doctors of all grades while on call.

Design-Pilot study of activity data self recorded by junior doctors, with the help of students during busy periods.

Setting-A general surgical firm and a general medical firm based at University Hospital, Nottingham.

Subjects-Four registrars, three senior house officers, and five preregistration house officers.

Results-Senior house officers and preregistration house officers spent nearly half of all their on call duty time working, but less than half of that time was spent in direct contact with patients. Registrars were on call more often than the house officers but spent less than one fifth of their on call duty time working, and almost two thirds of that time was spent in direct contact with patients.

Conclusions - Workload while on duty is excessive for both senior and preregistration house officers. Changes in some administrative procedures and employment of more non-medical staff during on call periods might reduce the time spent on non-clinical activities, thereby reducing the overall workload and allowing more time for patient contact.

\section{Introduction}

Recent evidence indicates that some junior doctors may be working in stressful conditions over long periods without sleep..$^{1-3}$ To identify when, where, and why junior doctors locally were working excessively the district general manager of the Nottingham Health Authority, supported by the then director of public health, commissioned this study.

\section{Subjects and methods}

The study was confined initially to two acute specialty firms, one general surgical and one general medical, which together comprised 12 junior doctors. Both firms were based at University Hospital, Nottingham, a large teaching hospital of roughly 1400 beds. Data were collected only during on call periods - that is, outside the normal 9 am to $5 \mathrm{pm}$ working week. The surgical firm was studied for 34 days and the medical firm for 27 days, and the study was conducted mainly in December 1989.

There was full cooperation of the participating doctors, who helped design the study. The collection of data relied mainly on self recording on detailed, pocket book size $(11 \times 15 \mathrm{~cm})$ forms. Participants recorded in detail all activities, including work, leisure, and sleep. In addition, they completed a separate form about each bleeper call received. During periods when participants did not have time to record their own information because they were too busy students shadowed them, asking questions and recording answers. 